\title{
Subsídio do sistema GTP (Geossistema- Território-Paisagem) na percepção de riscos ambientais: esboço metodológico $i$
}

\author{
Contributions of the Geosystem-Territory-Landscape (GTP) system to environmental \\ risk perception: a methodological outline
}

Contribuciones del sistema GTP (Geosistema-Territorio-Paisaje) a la percepción del riesgo ambiental: un bosquejo metodológico

\author{
Carlos Eduardo das Neves ${ }^{\mathrm{ii}}$ \\ Gilnei Machadoiii \\ Karen Carla Camargoiv
}

Recebido em 04/2017 - aceito em 07/2017.

\begin{abstract}
RESUMO: Com o crescimento contínuo, desigual e contraditório das cidades, fala-se muito em ocupação de áreas de risco ambiental. Estes riscos são os mais diversos e vão desde um simples alagamento às enchentes e desmoronamentos, causando prejuízos econômicos e mortes. Tendo isso em consideração, se tem realizado a análise destas áreas, levando em consideração todo o arcabouço teórico e metodológico desenvolvido na academia, porém, pouco é considerado a opinião dos moradores destas áreas, os quais deveriam ser vistos como os maiores conhecedores do assunto. Esta pesquisa tem por objetivo apresentar uma matriz criada com esse objetivo, o de identificar a percepção das pessoas em relação aos riscos existentes nas áreas em que moram, diferenciando-a da perspectiva dos técnicos que avaliam essas áreas. Sua confecção, aplicação e debate estão embasados nas concepções teóricas do sistema tripolar Geossistema, Território e Paisagem. Para testar a matriz em questão, a mesma foi aplicada em vinte pontos ao longo da bacia do Ribeirão Quati, Londrina - Paraná. Tal exercício mostrou que a mesma permite uma análise mais complexa das variáveis de perigo e vulnerabilidade (componentes do risco), gerando ferramenta relevante ao planejamento e gestão ambiental urbana.
\end{abstract}

Palavras-Chave: Percepção Ambiental, Matriz de análise de risco, Vulnerabilidade.

ABSTRACT: Due to the continuous, unequal and contradictory growth of cities, there has been much talk about occupying areas of environmental risk. The risks involved are the most diverse ones and can range from a simple flood to inundations and landslides, causing economic losses and deaths. In view of that, analyses of these areas have been carried out based on all available theoretical and methodological framework developed in the academia. However, little has been considered about the opinion of the residents living in these areas, who should be seen as the most knowledgeable people on the subject. This study aims to present a risk analysis matrix created with the objective of identifying the perception of people in relation to the risks existing in the areas where they live, which is a different perspective from that of the technicians who evaluate these areas. The development and application of this matrix and the debate around it are based on the theoretical conceptions of the tripolar system called Geosystem, Territory and Landscape (GTP, from French: Géosystème - Territoire - Paysage). As a test, the matrix was applied at twenty points along the Quati stream basin, in the city of Londrina, Paraná, Brazil. Finally, it was found the matrix allows for a more complex analysis of the variables of danger and vulnerability (risk components), becoming a relevant tool for urban environmental planning and management.

Key words: Environmental perception; Risk analysis matrix; Vulnerability. 
RESUMEN: Debido al crecimiento continuo, desigual y contradictorio de las ciudades, mucho se ha hablado de ocupaciones de áreas de riesgo ambiental. Estos riesgos son los más diversos y pueden ir desde un simple anegamiento a inundaciones y deslizamientos de tierra, causando pérdidas económicas y muertes. Teniendo esto en cuenta, esas áreas han sido analizadas sobre la base de todo el marco teórico y metodológico desarrollado en el ámbito académico. Sin embargo, poco se ha considerado sobre la opinión de los habitantes de esas áreas, los cuales deberían ser vistos como los mayores conocedores del asunto. Este artículo pretende presentar una matriz de análisis de riesgos creada con el objetivo de identificar la percepción de las personas en relación a los riesgos existentes en las áreas donde viven, diferenciándola de la perspectiva de los técnicos que evalúan esas áreas. La elaboración y aplicación de la matriz y el debate que la rodea se basan en las concepciones teóricas del sistema tripolar Geosistema, Territorio y Paisaje (GTP). Como prueba, se aplicó la matriz en veinte puntos a lo largo de la cuenca del arroyo Quati, en la ciudad de Londrina, Paraná, Brasil. Finalmente, se encontró que la matriz permite un análisis más complejo de las variables de peligro y vulnerabilidad (componentes de riesgo), generando una herramienta relevante para la planificación y gestión ambiental urbana.

Palabras Clave: Percepción ambiental; Matriz de análisis de riesgos; Vulnerabilidad.

\section{INTRODUÇÃO}

O levantamento da percepção que as populações têm sobre o que vem a ser uma área de risco tem sido realizado, em grande parte, por meio de entrevistas e/ou questionários, porém, cabe salientar, que o uso de matrizes para avaliação de impactos e riscos ambientais tem se mostrado muito versátil, particularmente quando usado em trabalhos de campo, em função da possibilidade de interação entre diversos componentes e parâmetros que são de grande valia ao planejamento e à gestão urbana.

Entretanto, as matrizes utilizadas, por vezes, carecem de duas prerrogativas: (1) Discussão teórica e metodológica que auxilie a análise mais aprofundada das variáveis que compõem o conceito de risco ambiental (ALMEIDA, 2011). (2) Falta de rigor conceitual e a pouca inserção da percepção das comunidades, o que tem comprometido a investigação dos riscos ambientais (SOUZA; ZANELLA, 2009).

Nesse cenário, objetiva-se, com esta pesquisa, compreender a aplicabilidade e correlação do modelo tripolar Geossistema-Território-Paisagem (GTP) junto à percepção de riscos ambientais. Modelo este que pode fornecer apoio à percepção e ao rigor conceitual necessário na utilização da temática supracitada junto ao planejamento e gestão urbana.

Assim, busca-se especificamente: (1) aproximar, a partir do GTP, a visão técnica e acadêmica da percepção das comunidades que sofrem os riscos ambientais; (2) saber quais as principais causas das variações na percepção e estimativa do risco; (3) compreender a correlação entre áreas de risco ambiental e grupos socialmente vulneráveis e (4) analisar como a percepção dos riscos ambientais pode auxiliar na prevenção de acidentes em áreas potencialmente degradadas. 
Para esse intento, foi elaborada uma matriz de avaliação ambiental que correlaciona o sistema GTP, o saber acadêmico e o popular com as variáveis do perigo e da vulnerabilidade. A matriz foi aplicada ao longo das margens esquerda e direita do Ribeirão Quati na área urbana do município de Londrina-PR, especificamente em vinte diferentes pontos, os quais estão potencialmente degradados e podem servir de parâmetro para avaliação de outras áreas de risco, além de servirem de parâmetro de avaliação da própria matriz.

Para o desenvolvimento dessa correlação partiu-se da ideia de que o sistema GTP é, sobretudo, um modelo para o estudo da complexidade geográfica, sendo assim, um sistema de conceitos para toda uma trajetória acadêmica. Desse modo, para desenvolver esta pesquisa escolheu-se as variáveis relacionadas ao risco (perigo e vulnerabilidade) e a percepção.

A partir da correlação do GTP com os riscos ambientais, auxilia-se a aplicação desse sistema junto à análise geográfica dos riscos e seu próprio desenvolvimento enquanto modelo teórico-metodológico de globalidade e interface. Para tanto, este artigo divide-se em seis tópicos que discutem: o risco ambiental e suas possibilidades de uso no planejamento e gestão urbana; a percepção enquanto parte integrante dos riscos; a possibilidade de uso e correlação do sistema GTP junto à temática; posteriormente apresentam-se informações sobre as áreas analisadas e os procedimentos metodológicos a serem utilizados, com destaque para a criação de uma matriz de avaliação de riscos ambientais.

\section{DESENVOLVIMENTO}

\section{O risco ambiental e sua utilização em áreas urbanas degradadas}

O conceito de risco está diretamente ligado à ideia de probabilidade de ocorrência ou não de um evento (social, tecnológico e/ou natural). A perspectiva de que algo possa vir a ocorrer (DAGNINO; CARPI JUNIOR, 2007). "Embora as definições e interpretações sejam numerosas e variadas, todos reconhecem no risco a incerteza ligada ao futuro, tempo em que o risco se revelará" (AMARO, 2005, p. 8).

Partindo da ideia de risco enquanto um objeto social, a principal referência para a sua avaliação é o próprio ser humano (DAGNINO; CARPI JUNIOR, 2007). Apesar de acreditar que "(...) não há risco sem uma população [ser social] ou indivíduo [ser biológico] que o perceba e que poderia sofrer seus efeitos" (VEYRET, 2007, p. 11), seria frágil esta análise se não considerássemos as dinâmicas físico-naturais, uma vez que o risco é a soma da presença direta das atividades antrópicas (vulnerabilidade) e as aleatoriedades ligadas à fragilidade, dinâmica e estrutura do 
sistema ambiental físico (perigo), pois segundo Marandola Jr. e Hogan (2004) estar em risco, é também estar suscetível a um perigo.

Devido à complexidade na conceituação de risco, escolheu-se nessa análise a noção de risco ambiental (Figura 1), pois os principais desastres ambientais ocorridos nos últimos 100 anos apresentaram estreita relação entre natureza sociedade e tecnologia, como bem destacado por Jacobi et al. (2011).

Assim, a conceituação de risco ambiental é de grande valia para esta análise, pois segundo Burton et al. (1993) é uma síntese que abriga o risco social, tecnológico e natural (Figura 1), podendo trazer uma visão holística acerca do risco. Nessa conceituação "[...] natureza, sociedade e tecnologia interagem" (SOUZA; ZANELLA, 2009, p. 19).

Figura 1 - Proposta de Classificação dos Riscos Ambientais

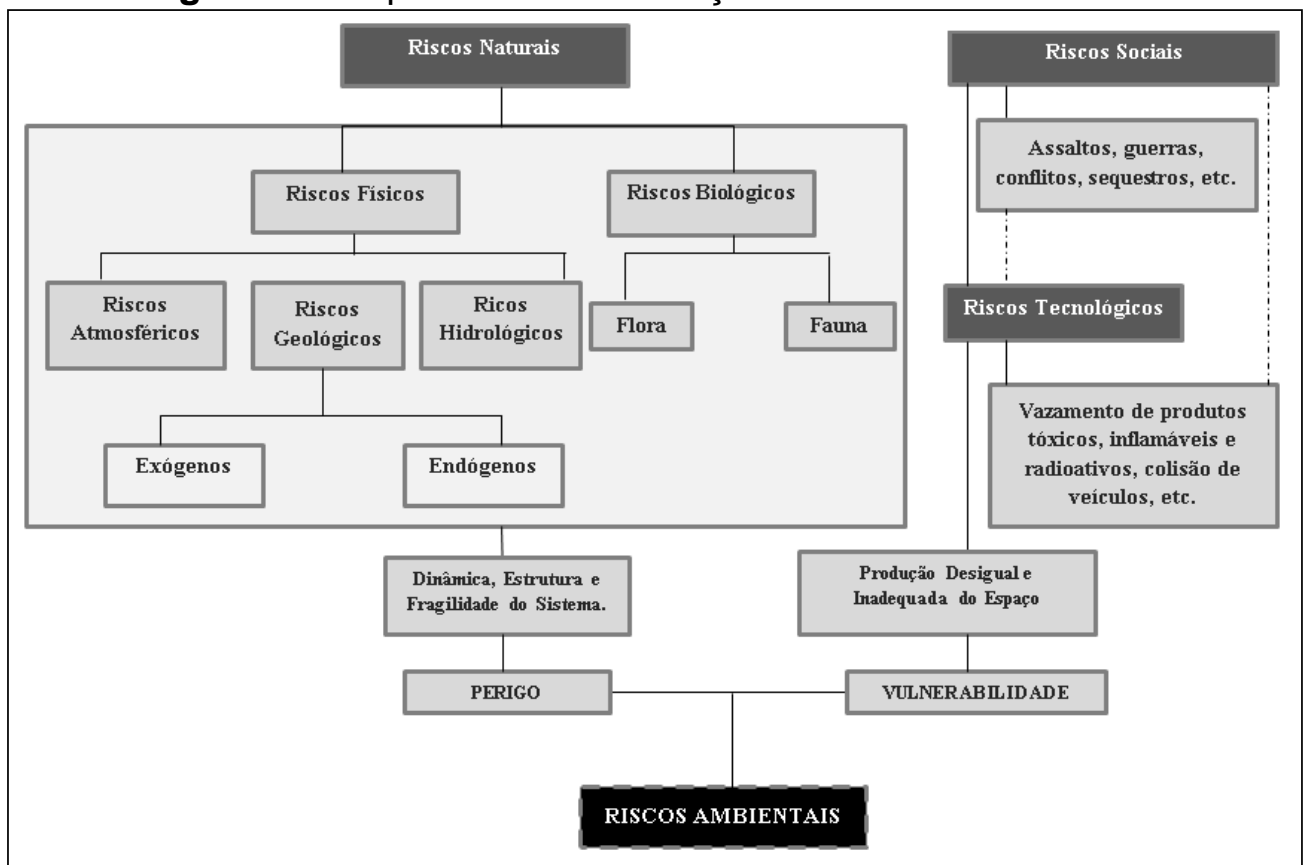

Fonte: Adaptada de Cerri e Amaral (1998, p. 302 apud SOUZA; ZANELLA, 2009).

Nesta pesquisa considera-se o perigo enquanto condições físico-naturais, ressaltando a suscetibilidade de uma determinada área a fenômenos adversos que colocam os homens em situações de ameaça. A vulnerabilidade refere-se à predisposição construída historicamente que aumenta a probabilidade de um indivíduo ou grupo de sofrer com ameaças segundo sua exposição, sensibilidade e resiliência aos fenômenos adversos (KASPERSON et al., 2005; TURNER et al., 2003). Por isso, o risco ambiental é uma resultante complexa da relação sociedade-natureza e do espaço-tempo, aproximando-se da ideia de riscos múltiplos. 
Giddens (1991) bem destaca que o risco da atualidade é fabricado pelas intervenções sociais e culturais, podendo auxiliar até na criação e intensificação de desastres tidos como naturais. Assim, as condições de vida das populações passaram a apresentar papel importante na constituição e compreensão dos riscos ambientais, especialmente em ambientes urbanos (MENDONÇA, 2004).

Cabe esclarecer que o risco ambiental é temporalmente anterior ao impacto, desastre ou catástrofe. Esta compreensão permite avaliar áreas de risco, segundo sua intensidade, duração e magnitude, e os impactos relacionados à população de maneira não naturalista (MENDONÇA, 2004), permitindo perceber a complexidade da noção de risco ambiental e sua relação com a produção do espaço geográfico contraditório e desigual.

\section{Percepção e Identidade na Análise dos Riscos Ambientais}

O risco é a percepção de uma comunidade ou individuo acerca da probabilidade da ocorrência de um evento potencialmente perigoso que seja causador de dano à mesma. Por percepção, entende-se aqui como sendo o

[...] ato ou efeito de perceber; combinação dos sentidos no reconhecimento de um objeto; recepção de um estímulo; faculdade de conhecer independentemente dos sentidos; sensação; intuição; ideia; imagem; representação intelectual, indo desde a recepção de estímulos até a intuição (MARIN, 2008, p. 206).

A análise dos riscos ambientais pode ser entendida através do olhar acostumado da sociedade que vive o risco, permitindo outra visão acerca do tema, distinta daquela do olhar especializado, técnico ou acadêmico.

Essa inserção de quem vive e que pode vir a sofrer o risco se torna essencial, especialmente quando são entendidas juntamente as variáveis da renda, escolaridade, círculos culturais e religiosos e sua relação com o ambiente (MARANDOLA JR.; MODESTO, 2012). Por isso, escolher diferentes áreas com perfis sociais e características naturais distintas se torna uma possibilidade de análise abrangente ao tema proposto.

Marandola Jr. e Modesto (2012) citam que a percepção é parte constituinte do próprio fenômeno de risco e é, desse modo, que será analisado na pesquisa, relacionando vulnerabilidade, perigo e percepção na perspectiva do GTP. 


\section{Geossistema-Território-Paisagem na Análise de Riscos Ambientais}

O sistema GTP - Geossistema (source), Território (ressource) e Paisagem (ressourcement) (BERTRAND; BERTRAND, 2007) se baseia em critérios de antropização $(G)$, de artificialização $(T)$ e de artialização $(P)$.

Bertrand e Bertrand (2007) apresentam o GTP, onde:

- O geossistema é visto enquanto o espaço-tempo da natureza antropizada (socializada), tal qual ele funciona atualmente, permitindo uma análise da estrutura e funcionamento biofísico do espaço geográfico. Este modelo expõe o geossistema enquanto um conceito naturalista com dimensão social;

- O território, está fundado sobre a apropriação e, portanto, representa o "limitar/cercar", refere-se ao espaço-tempo da sociedade, aquele da organização política, jurídica, administrativa. É assim, o "recurso" (ressource) no tempo curto e instável do mercado. Permite analisar as repercussões da organização e funcionamento socioeconômico sobre determinado espaço;

- A paisagem representa o espaço-tempo da cultura, da arte, da estética, do simbólico e do místico. Ela é o ressourcement de tempo longo, patrimonial e identitário.

No entanto, estudar essas três categorias, através do sistema GTP, é evidenciar que o pertencimento ao lugar, as relações culturais, as relações de poder sobre determinado espaço e o modo como se utiliza os elementos naturais se apresenta a partir de um jogo dialético que compõe um sistema integrado que é a face da nossa sociedade (NEVES, et al., 2014).

Essa aproximação é vista na Figura 2, que representa a correlação entre as variáveis analisadas e sua possibilidade de uso no planejamento e gestão de áreas de risco ambiental.

Através da correlação do GTP com a análise do risco ambiental é possível relacionar o perigo à dinâmica e estrutura do geossistema, mostrando como a antropização (sob o viés da socialização) da natureza é muito importante para o entendimento da intensidade e frequência das ameaças. O território permite aproximar a análise socioeconômica da vulnerabilidade, especialmente considerando a renda enquanto fator importante para a delimitação do conceito.

No entanto, destaca-se que a organização política, jurídica e administrativa também é relevante na análise. A paisagem permite aproximar a identidade da percepção dos moradores de áreas de risco ambiental, além de aproximar a percepção acostumada da comunidade do olhar do técnico/poder público. Através da paisagem realiza-se um olhar histórico acerca do território e da modificação do geossistema. 
Figura 2 - Sistema GTP e seus componentes de análise associados ao risco ambiental

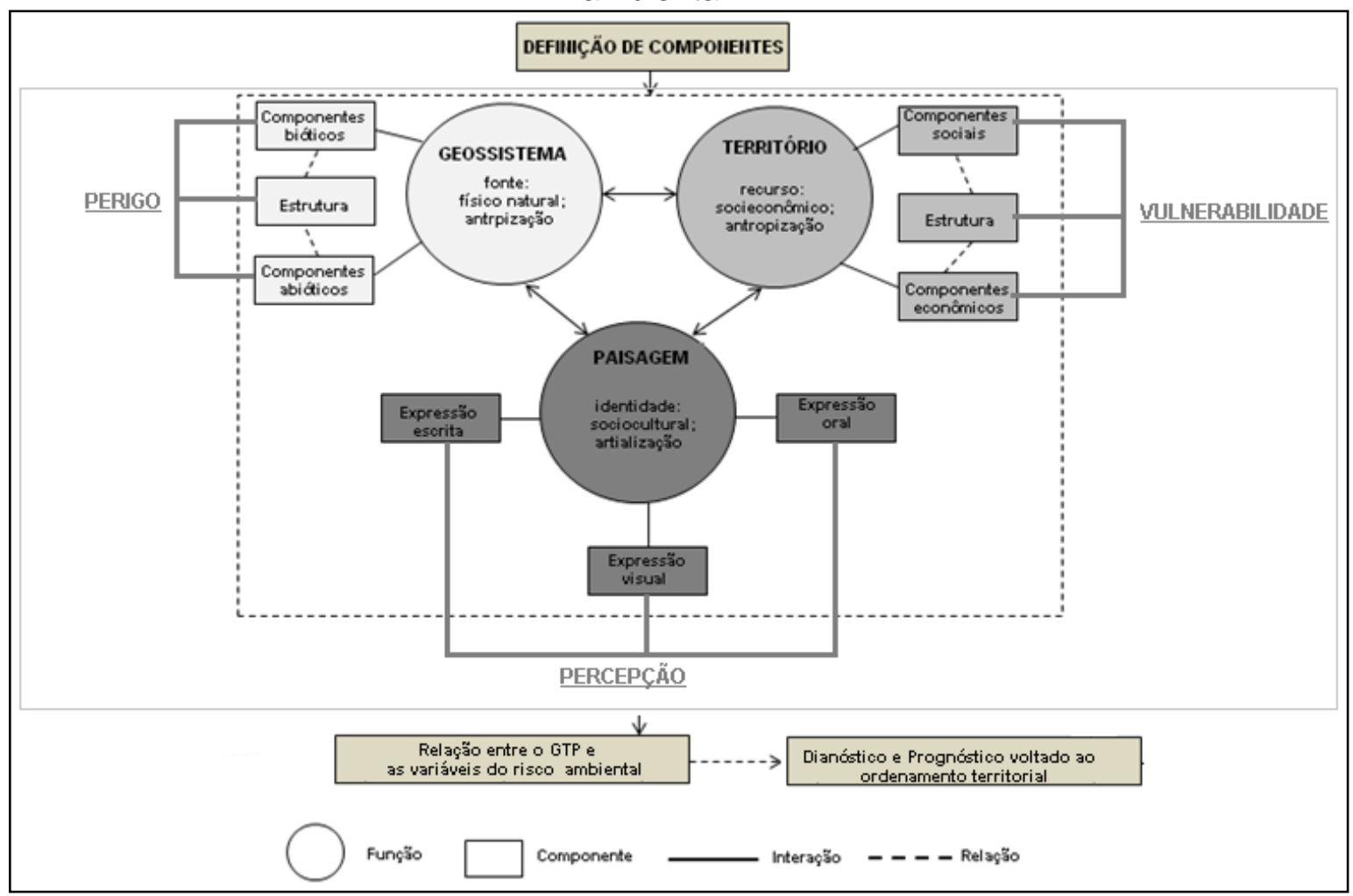

Fonte: Organizado por Neves (2015).

Entretanto, é a percepção que ganha lugar de destaque em nossa análise, pois a mesma é parte indissociável do risco, pois sem que o indivíduo perceba o risco, o mesmo não existiria. A percepção une o olhar acostumado acerca dos ritmos da natureza e a construção histórica da vulnerabilidade. Através da inserção da percepção na análise do risco ambiental segundo o sistema GTP é possível trabalhar com a característica do "pertence a mim" e "faz parte de mim" (MARANDOLA JR; MODESTO, 2012).

Portanto, o modelo considera antes de tudo a relação sociedade-natureza e o espaço-tempo, além de ser uma grande ferramenta para a delimitação e representação cartográfica de áreas de risco ambiental.

\section{Procedimentos de Análise e Criação da Matriz de Risco Ambiental}

Como dito anteriormente, em campo, foram analisadas, segundo os objetivos propostos, vinte pontos ao longo das margens esquerda e direita do Ribeirão Quati (Londrina-Paraná) (Figura 3), de modo a evidenciar processos e elementos associados aos riscos ambientais. Permitindo, assim, a avaliação da matriz elaborada, por meio de sua aplicação em distintas realidades de estabilidade do sistema físico 
natural, bem como ligado à resiliência de dada população, que deve ser diferenciada, pois cada classe social sente o risco de uma forma.

Em cada ponto representativo foi aplicada uma matriz de avaliação de riscos ambientais, criada com o propósito de subsidiar a inserção teórico-metodológica do sistema GTP e da percepção na identificação, análise e avaliação dos riscos ambientais.

Figura 3: Localização dos pontos de aplicação das matrizes

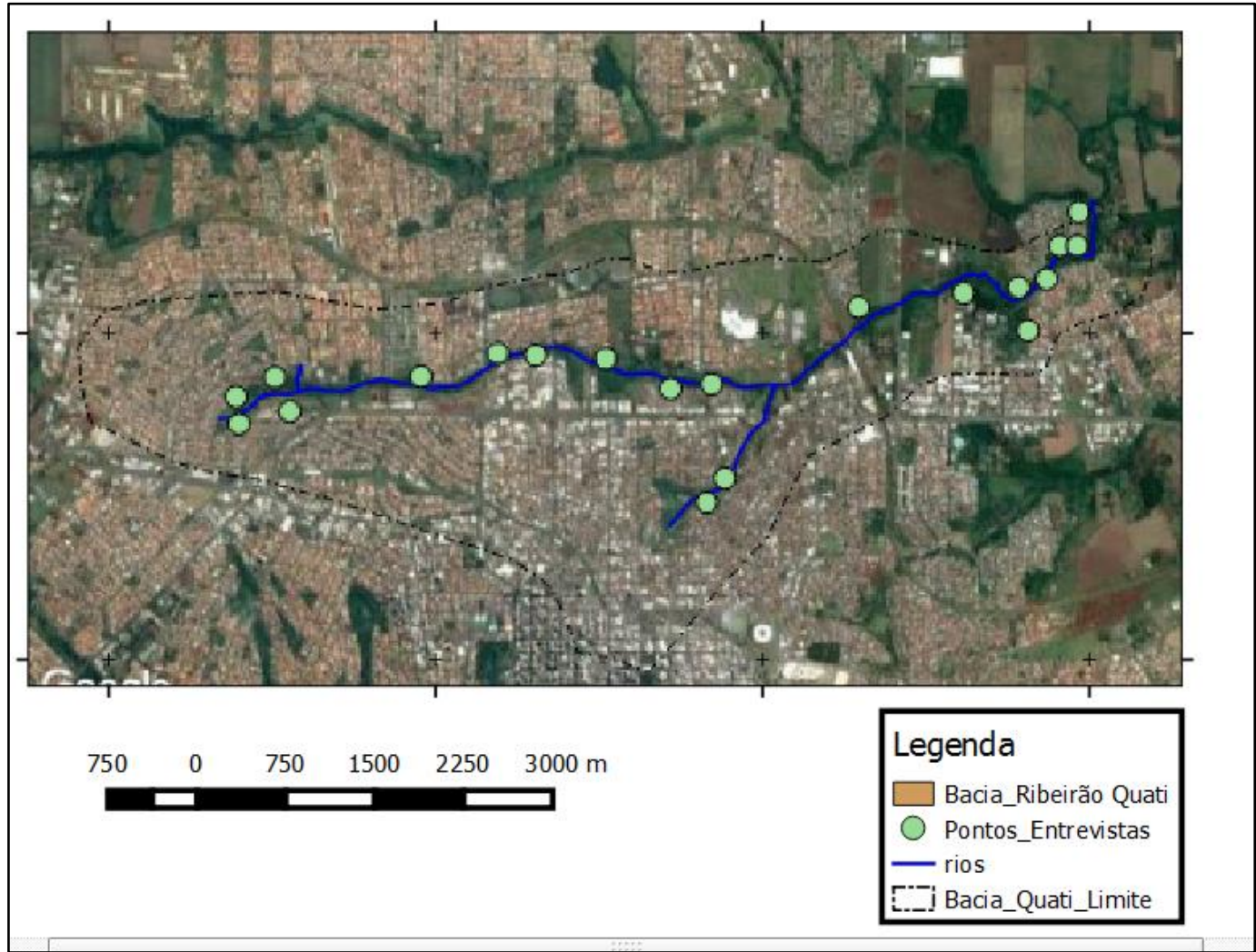

Fonte: Organizado por Machado; Neves e Camargo (2017).

A matriz classifica os riscos em: físicos e biológicos (perigo - geossistema), sociais e tecnológicos (vulnerabilidade - território), inserindo ainda como o técnico/acadêmico e a população percebem o risco (percepção como parte integrante - paisagem), onde a relação destes permitirá entender os riscos ambientais dos pontos analisados (Quadro 1).

Já avaliação desses "tipos" de risco é realizada a partir de variáveis de "Critérios de Potencial de Risco" (CPR), podendo ser direta (D), indireta (I) e não relacionada $(\mathrm{N})$, bem como por classes de impacto $(\mathrm{Cl})$, que são nesta análise a "Frequência", "Duração" e "Gravidade" dos eventos impactantes. Escolheram-se essas variáveis, visto que se relacionam diretamente com os prejuízos experimentados, sendo avaliada a partir das variáveis alta $(A)$, média $(M)$ e baixa (B) (Figura 4). 
Quadro 1 - Variáveis dispostas na matriz de risco ambiental

\begin{tabular}{|l|l|l|l|l|}
\hline $\begin{array}{l}\text { Totalidade } \\
\text { do conceito }\end{array}$ & Conceito & $\begin{array}{l}\text { Divisão dos } \\
\text { conceitos }\end{array}$ & Percepção \\
\hline \multirow{4}{*}{$\begin{array}{l}\text { Riscos } \\
\text { ambientais }\end{array}$} & $\begin{array}{l}\text { Perigo/ } \\
\text { Geossistema }\end{array}$ & Riscos físicos & $\begin{array}{l}\text { Percepção } \\
\text { do técnico/ } \\
\text { acaerenico }\end{array}$ & $\begin{array}{l}\text { Percepãa da } \\
\text { população/ } \\
\text { comunidade }\end{array}$ \\
\cline { 2 - 3 } & $\begin{array}{l}\text { Vulnerabilidade/ } \\
\text { Território }\end{array}$ & Riscos biológicos sociais & & \\
\cline { 3 - 3 } & & $\begin{array}{l}\text { Riscos } \\
\text { tecnológicos }\end{array}$ & \\
\hline
\end{tabular}

Fonte: Organizado por Neves (2015).

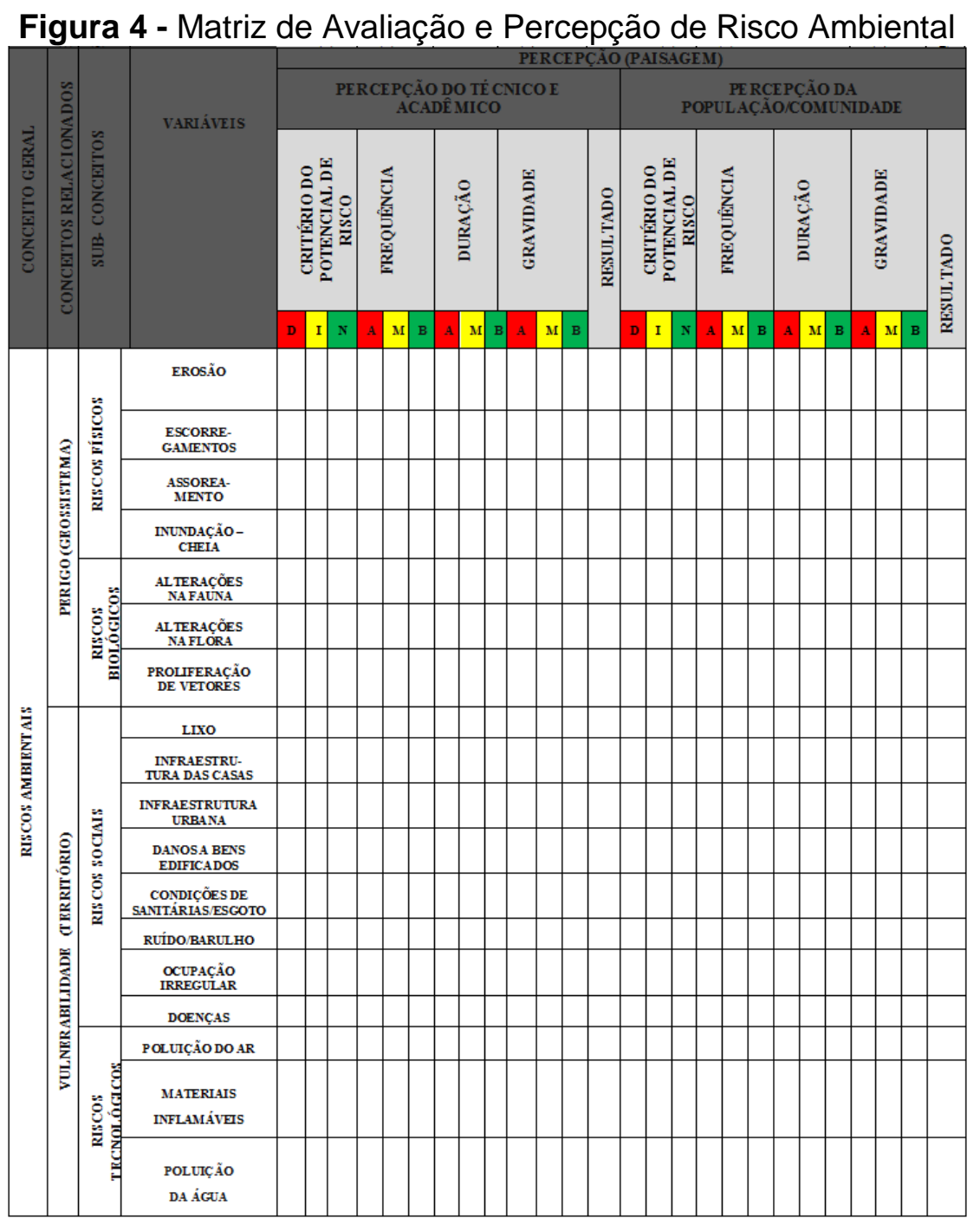

Fonte: Organizado por Neves (2015).

O uso do conceito de limiar de estabilidade homeostático é utilizado para destacar a atual situação dos pontos amostrados em relação ao perigo-geossistema. O mesmo refere-se até o momento em que o sistema é capaz de suportar as perturbações sofridas e manter suas características essenciais (DREW, 1986). 
Destacam-se, ainda, os conceitos de biostasia e resistasia de Erhart (1956), para entender a dinâmica sistêmica das áreas avaliadas. A biostasia refere-se ao estado de estabilidade vegetal com erosão fraca e transporte de sedimento pouco significativo e a resistasia faz referência à situação resultante da ruptura do equilíbrio biológico, onde a erosão e a sedimentação são mais significativas, especialmente devido à retirada da cobertura vegetal, com graves consequências ao sistema de drenagem, com destaque ao assoreamento dos cursos hídricos (CASSETI, 2005).

Para a avaliação das CPR e $\mathrm{Cl}$, realiza-se cálculo de porcentagem, partindo da contagem do número de vezes que determinada variável é citada nas matrizes, referentes aos riscos físicos (4 elementos), biológicos (3), social (8) e tecnológicos (3), destacando um total de 18 variáveis analisadas, conforme matriz (Figura 4). Exemplificando, se a CPR ou a Cl "alta" aparecer em 15 elementos do quadro as mesmas representarão $83 \%$.

\section{Aplicação no Ribeirão Quati - Londrina - Paraná: apontamentos iniciais de caminhos possíveis}

Muitas são as soluções apontadas ao equacionamento dos problemas ambientais urbanos. Todavia, tais soluções parecem ainda distantes da realidade desejada, sobretudo pela pouca participação social, juntamente ao fortalecimento do setor pública junto a avaliação e inserção no debate. Desse modo, a partir da aplicação da matriz, coopera-se com a diminuição de tal quadro, ao relacionar, universidade e sociedade na análise do quadro atual de áreas degradadas, em especial pela contradição sociedade - natureza da produção do espaço urbano.

Assim, a partir da aplicação da matriz em vinte pontos ao longo da bacia, seja em relação a perspectiva dos moradores (Figura 5) e/ou a dos técnicos/acadêmicos (Figura 6) indicou-se variáveis e áreas prioritárias para a intervenção. Visando sintetizar os dados levantados, realizou-se a união e correlação dos resultados de todas as matrizes aplicadas por ponto (1 ao 20), indicando um cenário parecido entre as visões dispostas nas figuras (5 e 6), pois entre os seis pontos visualmente mais degradados, quatro deles foram comuns para o morador e para o técnico/acadêmico, a saber: $\mathrm{P} 1, \mathrm{P} 2, \mathrm{P} 13, \mathrm{P} 14$.

Já em relação as variáveis, também houve consonância entre as duas visão (morador e técnico/acadêmico), com destaque as variáveis de poluição aérea, materiais inflamáveis (entulhos), lixo e proliferação de vetores, respectivamente. 
Figura 5 - Percepção dos Riscos Ambientais e Avaliação da Comunidade

\begin{tabular}{|c|c|c|c|c|c|c|c|c|c|c|c|c|c|c|c|c|c|}
\hline Variáveis & P1 & $\mathbf{P 2}$ & P3 & P4 & \begin{tabular}{|l|l|} 
P5 & P6 \\
\end{tabular} & \begin{tabular}{|l|l|} 
P7 & P8 \\
\end{tabular} & \begin{tabular}{|l|l|} 
P9 & P10 \\
\end{tabular} & P11 & P12 & P13 & P14 & P15 & P16 & P17P & \begin{tabular}{l|l}
$\mathrm{P} 18$ & $\mathrm{P}$ \\
\end{tabular} & P19 & P20 \\
\hline \multicolumn{18}{|l|}{ Erosão } \\
\hline \multicolumn{18}{|l|}{ Escorregamentos } \\
\hline \multicolumn{18}{|l|}{ Assoreamento } \\
\hline \multicolumn{18}{|l|}{ Inundação - cheia } \\
\hline \multicolumn{18}{|l|}{ Alterações na fauna } \\
\hline \multicolumn{18}{|l|}{ Alterações na flora } \\
\hline \multicolumn{18}{|l|}{ Proliferação de vetores } \\
\hline \multicolumn{18}{|l|}{ Lixo } \\
\hline \multicolumn{18}{|l|}{ Infraestrutura das casas } \\
\hline \multicolumn{18}{|l|}{ Infraestrutura urbana } \\
\hline \multirow{2}{*}{\multicolumn{18}{|c|}{ Danos a bens edificados }} \\
\hline & & & & & & & & & & & & & & & & & \\
\hline \multicolumn{18}{|l|}{ Ruído/barulho } \\
\hline \multicolumn{18}{|l|}{ Ocupação irregular } \\
\hline \multirow{2}{*}{\multicolumn{18}{|c|}{$\begin{array}{c}\text { Doenças } \\
\text { Poluicão do ar }\end{array}$}} \\
\hline \multicolumn{9}{|l|}{ Poluição do ar } & & & & & & & & & \\
\hline Materiais inflamáveis (entulhos) & & & & & & & & & & & & & & & & & \\
\hline Poluição da água & & & & & & & & & & & & & & & & & \\
\hline
\end{tabular}

Fonte: Organizado por Machado; Neves e Camargo (2017).

Figura 6 - Percepção dos Riscos Ambientais e Avaliação do Técnico/Acadêmico

\begin{tabular}{|c|c|c|c|c|c|c|c|c|c|c|c|c|c|c|c|c|c|c|c|}
\hline Variáveis & P1 & P2 & P3 & \begin{tabular}{|l|l|l|l} 
P4 & P \\
\end{tabular} & \begin{tabular}{l|l}
5 & $P$ \\
\end{tabular} & \begin{tabular}{l|l}
6 & $P$ \\
\end{tabular} & 7 F & \begin{tabular}{l|l}
8 & $P 9$ \\
\end{tabular} & P10 & P11 & P12 & $\mathbf{P 1 3}$ & P14 & P15 & P16 & P17 & P18 & P19 & $\mathbf{P 2 0}$ \\
\hline \multicolumn{20}{|l|}{ Erosão } \\
\hline \multicolumn{20}{|l|}{ Escorregamentos } \\
\hline \multicolumn{20}{|l|}{ Assoreamento } \\
\hline \multicolumn{20}{|l|}{ Inundação - cheia } \\
\hline \multicolumn{20}{|l|}{ Alterações na fauna } \\
\hline \multirow{2}{*}{\multicolumn{20}{|c|}{$\begin{array}{c}\text { Alterações na flora } \\
\text { Proliferacão de vetores }\end{array}$}} \\
\hline & & & & & & & & & & & & & & & & & & & \\
\hline \multicolumn{20}{|l|}{ Lixo } \\
\hline \multicolumn{20}{|l|}{ Infraestrutura das casas } \\
\hline \multicolumn{20}{|l|}{ Infraestrutura urbana } \\
\hline \multicolumn{20}{|l|}{ Danos a bens edificados } \\
\hline \multicolumn{20}{|l|}{ Condições de sanitárias/esgoto } \\
\hline \multicolumn{20}{|l|}{ Ruído/barulho } \\
\hline \multicolumn{20}{|l|}{ Ocupação irregular } \\
\hline \multicolumn{20}{|l|}{ Doenças } \\
\hline \multicolumn{20}{|l|}{ Poluição do ar } \\
\hline \multicolumn{20}{|l|}{ Materiais inflamáveis (entulhos) } \\
\hline Poluição da água & & & & & & & & & & & & & & & & & & & \\
\hline
\end{tabular}

Fonte: Organizado por Machado; Neves e Camargo (2017).

O marcante dessa consonância, entre moradores (que sentem os riscos) e os técnicos/acadêmicos (que se atentam e estudam) é a relação em porcentagem entre os tipos de risco, sendo eles de baixa, média e alta frequência, duração e gravidade, os quais indicam:

- Na perspectiva do morador: $73,88 \%$ indicam baixo potencial de risco com influência direta à sociedade, bem como a frequência, a duração e a gravidade 
dos fenômenos de perigo e vulnerabilidade; $6,38 \%$ apresentam médio potencial de risco e $19,72 \%$ de alto potencial de risco;

- Na perspectiva do técnico/acadêmico: $73,05 \%$ das respostas indicam baixo potencial de risco com relação e influência à sociedade, bem como sua a frequência, duração e gravidade dos fenômenos; já 12,50\% das variáveis apresentam médio potencial de risco e em $14,44 \%$ das variáveis presenciou-se um alto potencial de risco a tais fenômenos;

Observa-se que em relação ao potencial de risco baixo, há uma consonância entre as duas visões no que tange a bacia como um todo, o que demonstra o papel conjunto que essas duas esferas desempenham na análise do ambiente degradado ou não.

No entanto, os técnicos enxergaram mais potenciais médios e os moradores mais potenciais altos de risco, sugerindo que os moradores pelo fato de sofrerem a relação entre perigo e vulnerabilidade sentem o ambiente mais arriscado. Todavia, a indicação de vetores de doenças, tais como a dengue, foi um fato muito citado pelos moradores, algo que permite pensar no papel de ações públicas de conscientização, com destaque a veiculação midiática (espetacularização da morte), uma vez que no período ocorria forte apelo a tais casos.

Assim, ao analisar a percepção dos moradores enfatiza-se a sua identidade com a paisagem local, pois ele é conhecedor das oscilações da natureza e da influência da dinâmica territorial na dinâmica da bacia (fonte - geossistema) pelos agentes produtores do espaço, mas também acabam expressando as iniciativas e desejos externos, como também é vista da avaliação dos técnicos, os quais colocam na avaliação a sua carga e perspectiva filosófica de entendimento do ambiente. Por isso, a matriz deve ser um meio de avaliar, mas não um fim.

Expressa-se ainda, a falta de fiscalização que é evidente na área, pois é o despejo de materiais diversos (lixos e entulhos) e a consequente proliferação de vetores e contaminação do curso d'água que são indicadas como as variáveis com maior problema, estando essa população sujeita a uma série de doenças causada por vetores patógenos, já que muitas residências e locais de descanso estão próximas ao curso hídrico e desses pontos de descarte.

Portanto, diante desta breve analise, indica-se que através da matriz é possível subsidiar a gestão de áreas com alto potencial de risco ambiental, além de permitir a integração entre estratégias de comunicação, educação ambiental e participação popular junto à avaliação do risco, conforme pode ser visualizado na Figura 7, criando projetos e ações, sobretudo, nas variáveis mais presentes nas matrizes. 
Figura 7 - Desenvolvimento da análise do risco ambiental segundo aplicação de matriz de análise e as possibilidades de inserção

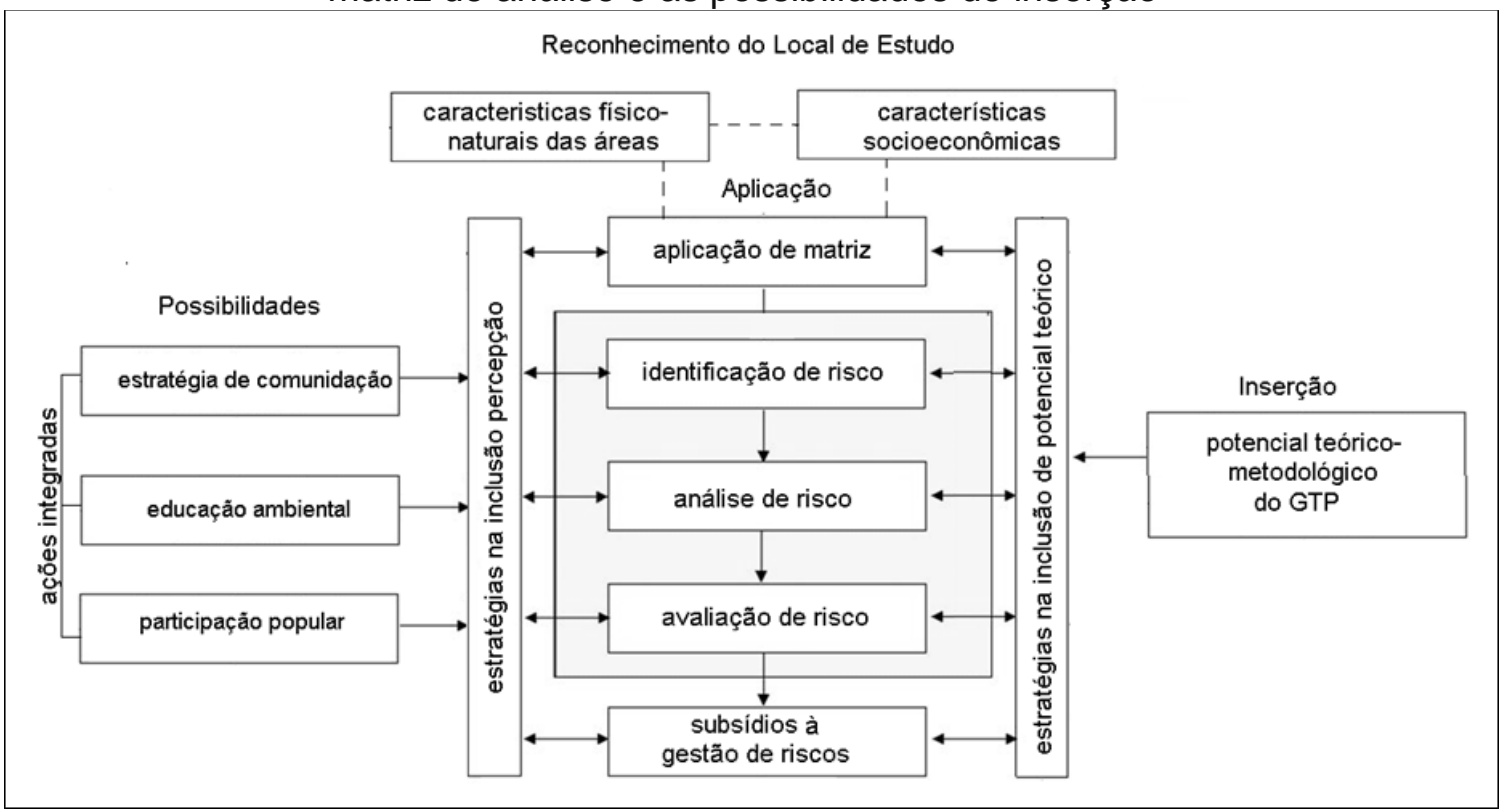

Fonte: Organizado por Neves (2015).

A matriz criada e aplicada permite compreender importantes problemas socioambientais urbanos, quando no momento da análise as variáveis escolhidas forem integradas pela análise do GTP. A união dos riscos naturais, sociais e tecnológicos, por meio do risco ambiental, permite entender problemas que se relacionam à suscetibilidade à disseminação de epidemias, violência urbana, desconforto ambiental, deseconomia urbana e custo ambiental. Portanto, apesar de escolher uma abordagem integrada para avaliação dos riscos no ambiente, desenvolve-se a análise sob a perspectiva de que não há risco sem individuo ou grupo que o sinta/perceba.

Dessa forma, apesar da necessidade de entendimento das dinâmicas e estruturas do sistema físico é o grau de vulnerabilidade socioespacial que é mais considerado nesta análise, sendo a percepção dos moradores, uma possibilidade de incluir a comunidade de forma integrada na identificação, análise e avaliação dos riscos ambientais que as afligem (Figura 8).

\section{CONSIDERAÇÕES FINAIS}

Com a finalização deste artigo, percebe-se que, além da escolha $e$ conceituação de risco ambiental e algumas inserções da vulnerabilidade (social) e do conceito de perigo para a explicação do conceito inicial, poderia ter se dado ênfase também à perspectiva do "impacto", pois o conhecimento deste seria imprescindível, especialmente na identificação do atual estado ambiental dos pontos coletados, 
variável física e quantificável. Essa inserção se dá, pois os impactos incidentes relacionam-se ao consequente agravamento das condições ambientais das áreas analisadas, por isso o debate sociedade - natureza ganha papel de destaque na aplicação e análise da matriz.

Figura 8: Exemplos de problemas ambientais que afligem a bacia do Ribeirão Quati

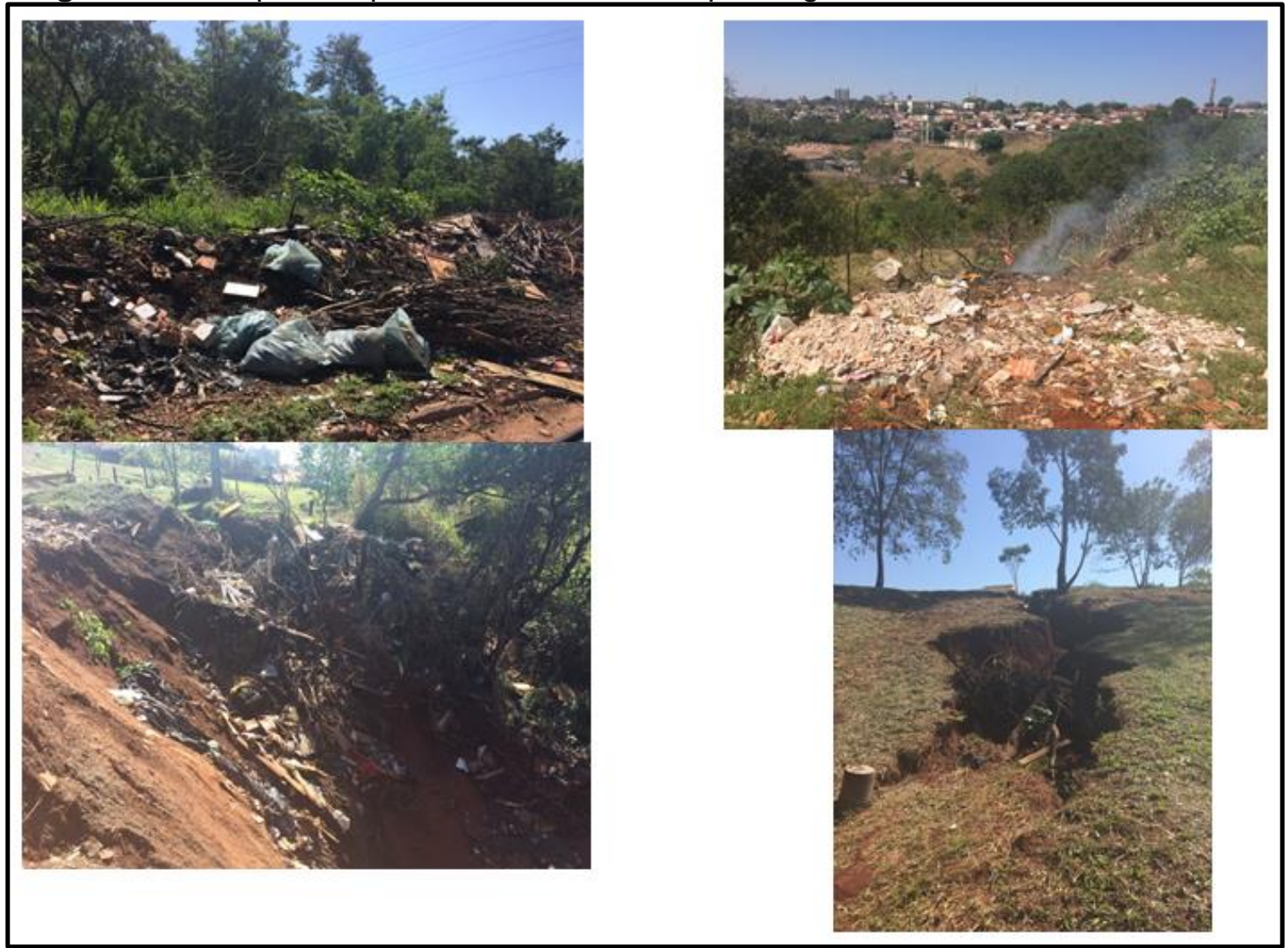

Fonte: Machado; Neves e Camargo (2017)

Outra questão a ser destacada é a necessidade de aprofundamento no conceito de "resiliência" para entender os ajustamentos, não só do sistema, mas, sobretudo, da população que vive o risco. Essa perspectiva pode auxiliar na análise da visualização ou não do risco ambiental enquanto conceito relacionado a dialética sociedade - natureza.

Nesse cenário, auxilia-se o GTP no que concebe seu desenvolvimento enquanto um modelo que visa a análise do espaço geográfico em sua transversalidade e ao conhecimento da totalidade e da interface de uma geografia integradora. Possibilita ainda, avaliar a correlação entre as implicações socioculturais $(P)$, econômicas $(T)$ e a manutenção da biodiversidade e geodiversidade ( $G$ ) diante do uso e cobertura da terra, evidenciando também a relação contraditória entre produção inadequada e desigual do espaço e a influência da fragilidade do ambiente na discussão do risco ambiental. 
No entanto, indica-se aos leitores que ao aplicarem a matriz de avaliação de risco ambiental, levem em consideração a classe social que é analisada na pesquisa, o gênero, a idade dos entrevistados, quanto tempo a pessoa reside no local, a convivência com o local e com outros moradores da área, visto que cada uma dessas variáveis, entre outras, possui papel relevante na análise dos riscos ambientais.

A maior coleta de pontos também pode expressar de maneira mais fiel a realidade da área. Tem-se que avaliar o que se vê e no mesmo lugar que se deve "aplicar/avaliar" com o morador, para haver uma similaridade da paisagem observada.

Acredita-se que é melhor falar com o morador primeiro e outro técnico (acadêmico) faz a análise, para não se influenciar com a resposta do morador, ou contraria-la. Portanto, quem aplica a matriz não pode ser o mesmo que avalia a área.

É necessário discutir a matriz anteriormente entre os técnicos que vão aplicala, para não gerar interpretações e indicações distintas. O item "não relacionado (N)" causa alguns transtornos ao averiguar as variáveis de frequência, duração e intensidade, devendo-se considerar, caso ocorra seu uso, graus de frequência, duração e intensidade baixo. Fala isso, pois o risco só ocorre quando é ligado e tem ações diretas à sociedade, a qual sente o risco.

Portanto, ao relacionar o GTP junto a matriz de avaliação de risco, possibilitou o entendimento inicial da abrangência e das limitações do mesmo junto à percepção do ambiente, contribuindo ainda, para uma análise mais complexa das variáveis perigo e vulnerabilidade que são extremamente relevantes ao planejamento e gestão ambiental urbana.

\section{REFERÊNCIAS}

ALMEIDA L. Q. Por uma ciência dos riscos e vulnerabilidades na geografia. Mercator Revista Geografia da UFC. v.10, n.23 p. 83-99, 2011.

AMARO, A. Para uma cultura dos riscos. Territorium, Coimbra, n.10, p. 113-120, 2003.

BERTRAND, G.; BERTRAND C. Uma Geografia transversal e de travessias: o meio ambiente através dos territórios e das temporalidades. Maringá: Massoni, 2007.

BURTON, I.; KATES, R.W.; WHITE, G. F. The Environment as Hazard. 2nd Edition. The Guilford Press, New York, 1993.

CASSETI, V. Geomorfologia. [S.I.]: [2005]. Disponível em: <http://www.funape.org.br/geomorfologia/>. Acesso em: 12 Jun. 2015.

DAGNINO, R. S.; CARPI JUNIOR, S. Risco Ambiental: conceitos e aplicações.

Revista Climatologia e Estudos da Paisagem Rio Claro, v. n. 2, p. 50-87, 2007.

DREW, D. Processos Interativos Homem Meio Ambiente. Tradução João Alves dos Santos. São Paulo; DIFEL, 1986.

GIDDENS, A. As Consequências da Modernidade. São Paulo, Edusp.1991. 
JACOBI, P. R.; RAUFFLET, E.; ARRUDA, M. P. Educação para a sustentabilidade nos cursos de administração: reflexão sobre paradigmas e práticas. Revista

Administração Mackenzie, v. 12, n. 3, Edição Especial. São Paulo, p. 21-50, 2011.

KASPERSON, R. E. et al. Vulnerable People and Places. In: HASSAN, R.; SCHOLES, R., et al (Ed.). Ecosystems and Human Well-bein: Current state and trends.

Washington, DC: Island Press, v.1, 2005. p. $143-164$.

MARANDOLA JR, E.; MODESTO, F. Percepção dos perigos ambientais urbanos e os efeitos de lugar na relação população-ambiente. Revista Brasileira de Estudos

Populacionais, Rio de Janeiro, v. 29, n. 1, p. 7-35, jan./jun. 2012.

MARANDOLA JR., E.; HOGAN, D. J. O risco em perspectiva: tendências e abordagens. Geosul, Florianópolis, v. 19, n. 38, p. 25-58, jul./dez. 2004.

MARIN, A. A. Pesquisa em educação ambiental e percepção ambiental. Pesquisa em Educação Ambiental, v. 3, n. 1, p. 203-222, 2008.

MENDONÇA, F; Riscos, vulnerabilidade e abordagem socioambiental urbana: uma reflexão a partir da RMC e de Curitiba. Revista Desenvolvimento e Meio Ambiente. N.10. p.139-148. Jul/dez. Curitiba: editora UFPR, 2004.

NEVES, C. E.; MACHADO, G.; HIRATA, C. A.; STIPP, N. A. F. A importância dos geossistemas na pesquisa geográfica: uma análise a partir da correlação com o ecossistema. Sociedade \& Natureza, v. 26, n. 2, p. 271-285, 2014.

SOUZA, L. B.; ZANELLA, M. E. Percepção de Riscos Ambientais: teorias e aplicações. Fortaleza, Edições UFC, 2009.

TURNER II, B. L. et al. A framework for vulnerability analysis in sustainability science. PNAS, v. 100, n. 14, p. 8074-8079, 2003.

VEYRET, Y. Os riscos. O homem como agressor e vítima do meio ambiente. São Paulo. Contexto, 2007.

\footnotetext{
' Artigo Vinculado ao Projeto Financiado pelo CNPq - "Caracterização ambiental das bacias hidrográficas urbanas de Londrina/PR para subsidiar a gestão pública municipal".

ii Mestre em Geografia pela UEL, Doutorando em Geografia pela FCT/UNESP - Bolsista de FAPESP - Proc. n. 2015/06558-9. E-mail: eduneves uel@hotmail.com

iii Professor dos Cursos de Graduação e Pós Graduação do Departamento de Geociências da UEL - DGEO/UEL. E-mail: gilmachad@gmail.com

iv Doutoranda em Geografia pela UEL.E-mail: karen.camargo@hotmail.com
} 